\title{
Style and Flow: \\ A Commentary on Duinker \& Martin
}

\author{
Jonah Katz \\ West Virginia University
}

\begin{abstract}
Duinker and Martin's excellent study presents a wealth of new data, findings, and analyses. It represents a welcome focus on the details of musical aspects of hip-hop, as well as an effort to combine those details with more global aspects of recordings in order to clarify what our notions of hip-hop 'style' or 'sound' are based on. The examination of instrumental backgrounds and production parameters is particularly novel. I would suggest, however, that the study could have benefitted from the use of details pertaining to flow, particularly in the examination of trends over time and stylistic sub-groupings. I show that several parameters pertaining to the complexity, rhythmic placement, and repetitiveness of rhymes help track changes in hip-hop style over time, distinguish between more and less similar songs, and capture effects of apparent time within the same actual time period.
\end{abstract}

Submitted 2017 June 20; accepted 2017 June 27, 2017.

KEYWORDS: hip-hop, corpus, flow, style, rhyme

CORPUS-BASED methods in the study of hip-hop have proliferated over the past 10 to 15 years (Kawahara, 2007; Katz, 2008, 2015; Hirjee \& Brown, 2010; Horn, 2010); culminating in two hip-hop corpus studies being published in the same issue of this journal in 2016 (Condit-Schultz, 2016a; Ohriner, 2016a) along with associated commentaries (Gran, 2016; Condit-Schultz, 2016b; Ohriner, 2016b). A third study now joins them: Duinker \& Martin's (2017) excellent examination of how musical, vocal, and production parameters factor into judgments of hip-hop 'style' or 'sound'. What all of these works have in common is a focus on the musical, rhythmic, semantic, or sonic details of hip-hop; to empirically-oriented music scholars and hiphop aficionados such as myself, this is a most welcome development. While most of the works cited above focus in narrowly on aspects of rhyme and/or rhythmic complexity in hip-hop, Duinker and Martin's study is concerned with musical style.

The authors ask several kinds of questions regarding the time period loosely known as the 'Golden Age' of hip-hop: what types of trends can be observed over this period? What general characteristics hold over the period? And what kinds of stylistic sub-groupings exist in music from the period? While I find the answers they provide to the first two types of questions quite interesting and plausible, I will suggest that their answers to the third type of question fall short in various ways. I will suggest that incorporating a few parameters at a greater level of detail pertaining to the rhyme and rhythmic factors examined in the earlier studies mentioned above could greatly improve not just the internal classification of Golden-Age hip-hop, but also the study of trends over time.

\section{METHODS}

In trying to draw a broad picture of hip-hop during the Golden Age, the authors base their corpus on a collection of 'best of' lists pertaining to hip-hop from 1986 to 1996. Condit-Schulz (2016a), Ohriner (2016a), and the commentaries on those papers all address sampling in a fair bit of detail, and I won't rehearse those discussions here. Suffice it to say that there could be a tension between attempting to be representative of hip-hop music at large and sampling based on either commercial or critical success. In particular, the lists used in Duinker and Martin's study contain a wide continuum of pieces between commercial blockbusters (e.g. Dr. Dre's 'The Chronic') and critical darlings who sold far fewer albums (e.g. $3^{\text {rd }}$ Bass). Including album sales as a variable in the corpus could potentially reveal interesting differences between more and less commercial types of hip-hop. 
Duinker and Martin classify the pieces largely on the basis of musical transcription as well as impressions of auditory salience and other properties. Using the researcher's perception as a guide to classifying corpus materials could of course be criticized, but it seems to me a reasonable place to start, and the authors are careful to suggest that impressionistic classifications should be subject to empirical confirmation in future work. This is the first corpus study I know of that features detailed transcriptions of instrumental background tracks in hip-hop, an area which certainly deserves more attention. The remaining parameters assigned to pieces involve voice quality and pitch, 'speech-likeness' of vocal rhythm, subject matter, and production qualities; this last category is also a first in the hip-hop corpus literature, I believe. One of the vocal parameters mentioned in the paper, the level of 'enunciation' or 'sharpness' of consonants, is somewhat baffling to me as a speech scientist. There surely are differences in the degree of lenition or reduction displayed by different speakers, but I do not recognize the examples given by the authors as related to this or any other obvious phonetic property I can think of.

For each of the parameters coded, the authors seek to examine whether that parameter displays patterns over time in the corpus, patterns of overall prevalence in the corpus, and sub-patterns that can help separate stylistic groupings within the corpus. The first two questions are fairly straightforward quantitative matters, but the final type of question necessitates a method of weighting the various classifying parameters to yield a single similarity estimate. It appears from the text that the authors set weights by hand on the basis of perceived 'salience' of the various parameters. The resultant clusters were compared to an ostensibly human-guided classification of the songs pulled from a music-review aggregator's website. Given that the results of the weighting scheme used here don't seem particularly impressive, I wonder if it would have been better to allow the statistical software to optimize weights based on the pre-existing classification from the web.

\section{RESULTS}

Duinker and Martin discover a number of interesting patterns in the corpus, many of which are novel. Tempo slowly decreases over time, replicating a finding from Condit-Schultz (2016a). Cursing, unsurprisingly, rises following the birth of 'gangsta rap', then levels off around 1992. Overall loudness and compression both rise over time. Tempos tend to be clustered near what music-cognition literature suggests are preferred values (around $100 \mathrm{bpm}$ ). Songs with tonal accompaniment tend to be in minor keys. I would be interested to see a classification of the instrumental tracks into rough genres. For instance, the authors illustrate the musical accompaniment to A Tribe Called Quest's 'Bonita Applebaum' and Coolio's 'Gangsta's Paradise'. While the former is classified as chromatic and the latter as tonal, there is an equally salient difference in genre here. 'Bonita Applebaum' features suspended chords on an electric piano that clearly evoke 60s and 70s jazz, while 'Gangsta's Paradise' is based on Stevie Wonder's 'Pasttime Paradise' and clearly evokes gospel and classical music. Though not every instrumental track would be so easy to classify, it would be interesting to see whether and how the genres from which instrumental tracks are sampled or created change over time.

Of particular interest here are a cluster of related findings about musical form and instrumental background. The prevalence of long chorus sections, correlated with the presence of singing, begins rising sharply around 1990-92. The prevalence of instrumental sampling declines sharply over the same period. This could be seen as indicating a general shift away from a distinctly hip-hop aesthetic of mostly sampled instruments and continuous forms to more pop-flavored live instruments, singing, and verse-chorus forms. The authors relate the decline of sampling to a prominent lawsuit involving Biz Markie. I suspect that some of this cluster of results, however, comes from a trend in hip-hop or at least in this sample towards the end of the relevant period. There are relatively few pieces from 1995 and 1996 in the corpus, but this small collection includes a number of innovative artists known for their musical skill with instruments and/or singing, such as the Roots, Fugees, and the Pharcyde. This seems to me to be part of a general broadening and diversification of hip-hop in the early 1990s, which I generally take to be the end of the 'old school' and the Golden Age of hip-hop.

This relates to what I think is a point of broader interest in this area. My impression as a hip-hop fan has always been that there was something of a revolution in the music that started around 1992 or 1993 and was complete by 1995 or so. Duinker and Martin's corpus spans this boundary, and several of the variables they study appear to show sharp discontinuities at or just before 1992. It would be interesting to clarify this shift, but I suspect that for progress to be made, we need to consider flow, which I use to refer to (at least) rhyme and rhythmic properties of hip-hop vocals. Several of the artists in this corpus, including the Pharcyde, the Wu-Tang Clan, and Nas, released debut albums in the period from 1992-1994 that to my mind constitute 
a definitive break with flow conventions of earlier hip-hop. To see whether variables pertaining to flow could help differentiate and classify the music in the corpus, I did a few transcriptions and analyses to test my intuitions.

\section{FLOW AND STYLE}

Duinker and Martin make the eminently reasonable decision not to wade into the details of vocal rhythm and rhyme in their paper. The decision is reasonable because these aspects of hip-hop are particularly complicated, hard to code objectively, and very time-consuming to analyze. Nonetheless, I think a full accounting of styles and subgenres is impossible in the absence of information pertaining to flow. As a longtime hip-hop listener, it seems obvious to me that this is a major factor in the novelty, complexity, and stylistic affinity of hip-hop artists and songs. There are several pieces of empirical evidence to back this up. Rhythmic regularity in this genre refers to rapped musical groups (in the sense of Lerdahl \& Jackendoff, 1983) that are of roughly similar duration, and that occur with similar alignment to the musical metrical structure. Old-school rap, from a period roughly up to the late 1980s, tends to be fairly rhythmically regular: linguistic groups tend to be of roughly equal length and aligned to similar positions in metrical structure. This can be seen in transcriptions of a 1984 Curtis Blow song (Adams, 2009) or excerpts from a 1986 Run DMC song (Katz, 2015), for instance. Rhymes in these songs also tend to be at the ends of linguistic groups; given this tendency and the tendency of groups to be regular with respect to meter, the location of rhymes is fairly predictable within this time period. Later music begins to relax all of these constraints on alignment, grouping, and rhyme placement: see, for instance, Walser's (1995) analysis of Chuck D.'s 1988 performance on 'Fight the Power', Pihel's (1996) partial transcription of a Big L piece from the early 1990s, and Horn's (2010) account of rhyme placement in the 1990s recordings of Snoop Dogg. By the time of the music sampled by Katz $(2008$, 2015), from 1993 to 2007, there is a high level of freedom with regard to the length of linguistic groups, their alignment to metrical structure, and the placement of rhymes within grouping or metrical structure. I chose that sample based on perceived complexity and unpredictability of rhymes, and the paper gives several illustrations of complex alignment. Many of these apparent trends over time are confirmed by Condit-Schultz's (2016a) study on a larger corpus. So there are good reasons to think that flow began to change in far-reaching ways in the late 1980s and early 1990s, and that these changes are an important part of hip-hop style. I briefly illustrate this below with two songs from the corpus, then progress to a slightly wider set of comparisons.

\section{RUN DMC AND NAS: A FLOW COMPARISON}

I chose two songs from opposite temporal ends of the corpus that seem to me to illustrate differences between older and newer flow styles. Run DMC is a pioneering group in early hip-hop; their 1986 song 'Peter Piper' is an up-tempo classic that was considered risque at the time. Nas is one of the emcees who I described above as being part of the 1992-94 'flow revolution' that transformed hip-hop. 'The World is Yours' is from his 1994 debut album 'Illmatic', which is widely considered a masterpiece. The most straightforward prediction here is that rhymes should be more complex, less rhythmically predictable, and less uniform in the later song than the earlier one. For each song, I picked out all of the rhymes I could identify and transcribed their rhyme domains, the sequence of phones that participate in the rhyme relation. In English, rhyme domains can be smaller (flavor - behavior) or larger (ruin - flew in) than a word. The question of what 'counts' as a rhyme in hip-hop is a vexed and possibly intractable one (see Katz, 2015; Condit-Schultz, 2016a; and Ohriner, $2016 \mathrm{~b}$ for three different views on the issue); for this exercise, I just used my intuition. Because we're mainly concerned with comparisons between songs, rather than absolute levels of rhyme or rhythmic complexity, this choice seems appropriate to me.

With the rhymes singled out, I notated some features that correspond to various aspects of rhyme complexity, rhyme-scheme regularity, and rhyme placement predictability. Position is the metrical position of the first syllable of a rhyme domain, in terms of $16^{\text {th }}$ notes within a measure. Because first syllables of rhymes tend to be rhythmically prominent, and are often final in musical groups, this measure will reveal something about the alignment of rhythmic prominences and group boundaries with metrical structure. Distance is the distance between successive rhyme domains in a rhyme chain, also in $16^{\text {th }}$ notes. Highly regular and metrically stable rhyme styles will tend to have distances clustered around a few values (mostly 8 and 16) associated with prominent metrical levels. Syllable count is the number of syllabic nuclei in a rhyme domain (the examples in the preceding paragraph both involve two syllables); this is one measure of 
rhyme complexity. A number of logical variables were also coded. Final indicates whether the rhyme in question is the last stressed syllable of the last group contained in a measure; because the canonical placement of a rhyme is (roughly) final in a measure, this is an indication of how predictable rhyme placement is. Furthermore, because non-final rhymes often unfold separately from concurrent final rhymes (see Katz, 2015 for illustrations), this measure will tend to capture cases where there is more than one rhyme scheme occurring at once. Parallel indicates whether or not the rhyming pair in question occupies positions that were part of a rhyme in the preceding 2 measures; it is an index of how repetitive rhyme schemes are in a song.

Histograms of rhyme placement in 'Peter Piper' and 'The World is Yours' are shown in Figure 1.

Rhyme placement: Run DMC

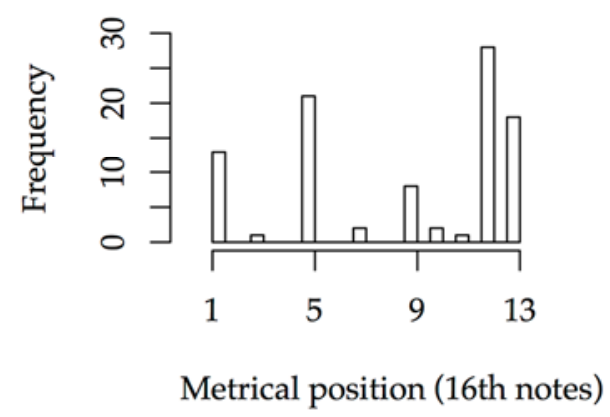

Rhyme placement: Nas

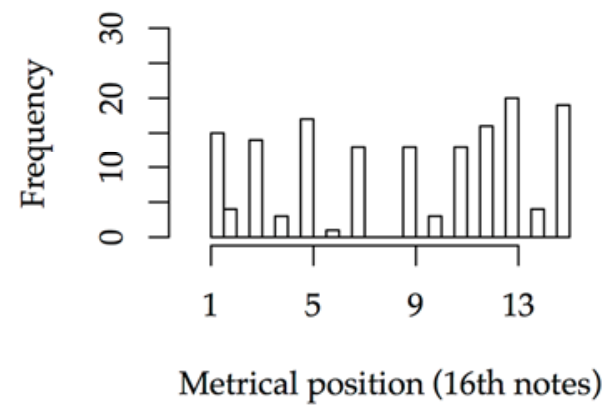

Fig. 1. Metrical position of rhyme domains in 'Peter Piper' (left) and 'The World is Yours' (right).

There are several notable patterns here. Run DMC displays modes on all 4 beats, as well as the $16^{\text {th }}$ note immediately preceding the $4^{\text {th }}$ beat (this is an anticipation). There are relatively few rhymes in any other metrical position, and many positions never host rhymes in this song. Nas, while displaying modes on the 4 beats as well, also displays a number of other modes, and almost every metrical position hosts a rhyme at some point in the song. In other words, the placement of rhymes is far more variable in 'The World is Yours', as we would expect. For this comparison and the ones to come, it will be useful to have a single quantitative index of how 'modal' vs. 'spread' a histogram is. I decided on the Gini coefficient, which economists use as a measure of income inequality. It measures the extent to which a frequency distribution departs from a model where every entity has an equal share of the measured quantity. The statistic ranges between 0 and 1 , where higher values indicate more inequality. The measured quantity here is rhyme occurrence, and the entities sharing it are metrical positions. By analogy with income inequality, if a few fortunate metrical positions are hogging more than their fair share of the rhyme occurrences, the Gini coefficient will be relatively high. Where rhyme occurrence is split more equally amongst metrical positions, the Gini coefficient will be relatively low. The Gini coefficient for 'Peter Piper' is 0.56 ; for 'The World is Yours', it is 0.34. This confirms the impressionistic description of the histograms and shows that the Gini coefficient is a useful summary of this particular kind of metrical variability.

I conducted the same analysis for the distance between rhyming pairs. The Gini coefficient for 'Peter Piper' is 0.63 ; for 'The World is Yours', it is 0.45 . Histograms are shown in Figure 2. This confirms that the metrical distance between domains in a rhyme relation is more variable (in the specific sense of being more evenly spread across values) in the later song than the earlier one. In particular, the vast majority of distances in 'Peter Piper' are 4, 7, 8, or $1616^{\text {th }}$ notes, while 'The World is Yours' displays more variety. 
Rhyme distance: Run DMC

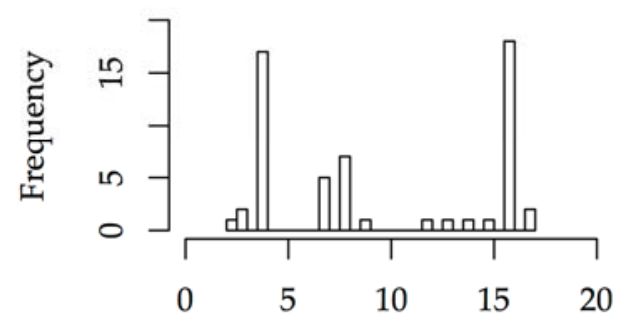

Distance between domains (16th notes)
Rhyme distance: Nas

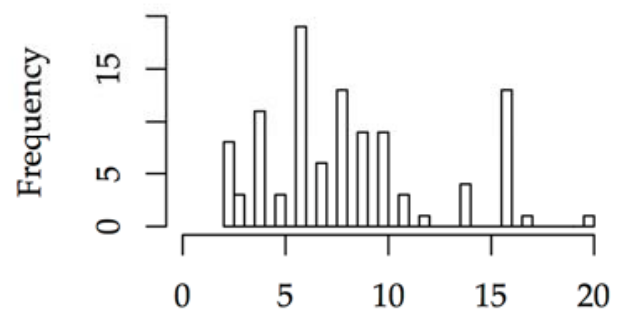

Distance between domains (16th notes)

Fig. 2. Metrical distance within rhyming pairs in 'Peter Piper' (left) and 'The World is Yours' (right).

The remaining metrics are shown in Table 1. The Nas song from 1994 has more multisyllabic rhyme domains, a smaller proportion of group-final rhyme correspondents, and less metrical parallelism between successive rhyme schemes than the Run DMC song from 1986.

Table 1. Mean number of syllables, proportion of final rhymes, and proportion of parallel rhyme schemes in 'Peter Piper' and 'The World is Yours'.

\begin{tabular}{l|c|c} 
& Run DMC & Nas \\
\hline Syllables & 1.31 & 1.50 \\
Final & 0.49 & 0.29 \\
Parallel & 0.38 & 0.10
\end{tabular}

All of these results suggest that the later song displays greater complexity than the earlier one in terms of rhyme structure, placement, and predictability. Several of these results replicate Condit-Schultz's (2016a) findings, and they suggest that flow is a promising approach to tracking the historical development of the material contained in Duinker and Martin's corpus. I set out to analyze a few more songs in order to 'fill in' the time trend a bit, and I selected songs that I thought would also shed light on Duinker and Martin's classification model.

\section{CLASSIFYING WITH AND WITHOUT FLOW}

The model that Duinker and Martin use to classify the songs in their corpus into sub-genres gets a number of things right, but also seems to get some things obviously wrong. Just looking through the first sub-group, for instance, the maximal similarity assigned to House of Pain's 'Jump Around' and the Pharcyde's 'Runnin', seems quite implausible, as does the pairing of Arrested Development's 'Tennessee' with Snoop Dogg's 'Gin and Juice'. One possibility is that the weighting scheme for the many variables used here just needs to be adjusted or optimized to deliver more sensible results. For instance, the instrumental backgrounds, tonalities, subject matters, and vocal pitch ranges of 'Runnin', and 'Jump Around' are quite different; perhaps these parameters just weren't weighted highly enough in the classification model. I decided, however, to see whether flow metrics could shed any light on the problematic classifications.

I chose 'Jump Around' and 'Runnin' because they cover two new years in the corpus (1992 and 1995, respectively) because I expected the Pharcyde to show very distinctive flow traits, and because I happen to know both songs well, which makes transcription and analysis much quicker. While this comparison can give us a rough feel for how similar the flow styles are in the two songs, it would be more useful if it could be compared to a pair of songs that do seem sensible as a subgenre pairing. For this purpose, I also analyzed Cypress Hill's 1993 'Insane in the Brain', which seems like a much better match for 'Jump Around'. The instrumental backgrounds are similar (accompaniments were produced by the same person, DJ Muggs of 
Cypress Hill), the overall themes and lyrics are reasonably similar, and the flow seems pretty comparable. Metrics for all three songs are shown in Table 2.

Table 2. Gini coefficients for position and distance distributions, mean number of syllables, proportion of final rhymes, and proportion of parallel rhyme schemes in the selected songs by the Pharcyde, House of Pain, and Cypress Hill.

\begin{tabular}{l|c|c|c} 
& Pharcyde & HOP & CH \\
\hline Position Gini & 0.46 & 0.43 & 0.53 \\
Distance Gini & 0.39 & 0.59 & 0.45 \\
Syllables & 1.51 & 1.33 & 1.33 \\
Final & 0.42 & 0.43 & 0.42 \\
Parallel & 0.07 & 0.14 & 0.11
\end{tabular}

For the distance distribution, syllable count, and parallelism metrics, the House of Pain song is closer to the Cypress Hill one than it is to the Pharcyde one, as expected. The finality metric is roughly the same for all three songs. The position distribution results are the opposite of what what we expected: more similarity between the Pharcyde and House of Pain than between House of Pain and Cypress Hill. On closer inspection, it does seem that the Pharcyde and House of Pain have similar degrees of clustering in rhyme position, but the actual positions where rhymes occur are somewhat different. As a follow-up test, I computed correlations between the frequency profile of House of Pain and those of the two other songs. Here, results are as expected: the distribution of rhymes is more similar between House of Pain and Cypress Hill $(r=0.92)$ than it is between House of Pain and the Pharcyde ( $\mathrm{r}=0.65)$.

It is worth comparing these new results to the earlier 'benchmark' ones for Run DMC (1986) and Nas (1994). As expected, both House of Pain (1992) and Cypress Hill (1993) come out intermediate between the earlier and later song on most measures. The Pharcyde (1995) come out intermediate on two measures and closer to Nas on the other three. This suggests that flow metrics may be a useful tool for tracking trends over time in the corpus. That said, I do not expect a straightforward or exceptionless relationship between the year of a recording and flow complexity, because many things affect flow complexity. In particular, flow may be more related to the age of a rapper than the age of a song. As a final exercise, I investigate this below.

\section{FLOW AND TIME}

In linguistics, the notion of apparent time is used to describe cases where a linguist believes that some feature has changed over time, but the evidence comes from differences between speakers of different ages being observed at the same time, rather than direct historical observation of an earlier and later value for the feature. The concept should be equally applicable to hip-hop flow. I chose two songs from 1993 to compare to Cypress Hill's 'Insane in the Brain', also from 1993. A Tribe Called Quest is an influential group associated with the birth of the 'conscious hip-hop' movement in the 1980s, and 'Award Tour' is a popular song from their third album. Wu-Tang Clan is a ground-breaking, distinctively odd, and arguably sui generis collective that rose to prominence during the 1990s; 'Protect Ya Neck' is from their debut album. A Tribe Called Quest is known as an old-school group; their music, lyrics, and flow reflect the aesthetic of 1980s hip-hop in some way. Wu-Tang is decidedly not old school; their debut album was a decisive break from many of the lyrical, musical, and flow conventions of earlier hip-hop. Cypress Hill, to my mind, is neither as old-school as Tribe nor as innovative as Wu. For a quick and dirty sanity check on this intuition, I turned to Google. About $93 \%$ of the pages that mention Tribe also contain the phrase 'old school' $(431 \mathrm{k} / 463 \mathrm{k})$; the figure is about $73 \%$ for Cypress Hill (312k/428k) and only 5\% for Wu Tang $(728 \mathrm{k} / 14.5 \mathrm{~m})$. So despite all three songs being recorded in 1993, I expected that they would lie on a continuum from older to newer flow styles. Results are shown in Table 3.

Table 3. Gini coefficients for position and distance distributions, mean number of syllables, proportion of final rhymes, and proportion of parallel rhyme schemes in the selected songs by A Tribe Called Quest, Cypress Hill, and Wu-Tang Clan. 


\begin{tabular}{l|c|c|c} 
& Tribe & $\mathbf{C H}$ & $\mathbf{W u}$ \\
\hline Position Gini & 0.56 & 0.53 & 0.41 \\
Distance Gini & 0.56 & 0.45 & 0.48 \\
Syllables & 1.34 & 1.33 & 1.25 \\
Final & 0.61 & 0.42 & 0.37 \\
Parallel & 0.16 & 0.11 & 0.08
\end{tabular}

As expected, Cypress Hill lies between Tribe and Wu-Tang on 3 out of the 5 measures. On each, Wu-Tang is classified as more complex and Tribe as less complex. For the distance distributions, none of the 3 songs are much different from one another. For syllable count, Wu-Tang is surprisingly low, lower than any of the other artists considered so far. This may be an idiosyncratic feature of their style or may just be an unusual feature of this particular song. In any case, I take these results to at least partially support the idea that there is a continuum of older and newer styles at play at any given moment in hip-hop history, and that flow is a useful window into this domain. Note that flow measures for Tribe are very similar to those for Run DMC with the exception of parallelism, and that measures for Wu-Tang are very similar to those for Nas and the Pharcyde with the exception of syllable count. This provides support for the claim that these changes over apparent time are tracking changes over actual time from the earlier analyses. The results here are also interesting because they show that flow metrics capture information about development and innovation in hip-hop that cannot be captured by dates alone.

\section{CONCLUSION}

Duinker and Martin's study has many positive qualities, and the authors are to be applauded for their careful, musically-informed approach. The study does, however, appear to me to neglect a few aspects of hip-hop style, especially as it pertains to similarity-based sub-groupings. I have shown here that local details related to flow have an important contribution to make to the study of hip-hop style over actual and apparent time. I think the most promising approach to increase our understanding of the structure, cognition, and aesthetics (including style) of hip-hop is to combine the more global measures used by Duinker and Martin with more local ones of the type I have introduced here. I chose a relatively simple and easy-to-code subset of features, but Condit-Schultz (1996a) introduces a wealth of more elaborate and/or rigorous metrics, including more detail on rhythm and metrical alignment. It would be exciting to explore the relative importance of all of these variables in describing, classifying, and tracking changes in a large corpus such as Condit-Schultz's or Duinker and Martin's.

\section{NOTES}

[1] Correspondence can be addressed to: Jonah Katz, Dept. of World Languages, Literatures, \& Linguistics, WVU, Chitwood Hall, Morgantown, WV 26501. Email: katzlinguist@gmail.com.

\section{REFERENCES}

Adams, K. (2009). On the metrical techniques of flow in rap music. Music Theory Online, 15(4).

Condit-Shultz, N. (2016a). MCFlow: A digital corpus of rap transcriptions. Empirical Musicology Review, 11(2), 124-147. https://doi.org/10.18061/emr.v11i2.4961

Condit-Shultz, N. (2016b). Commentary on Ohriner (2016). Empirical Musicology Review, 11(2), 180-184. https://doi.org/10.18061/emr.v11i2.5475

Duinker, B., \& Martin, D. (2017). In search of the Golden Age hip-hop sound (1986-1996). Empirical Musicology Review, 12(1-2), 80-100. https://doi.org/10.18061/emr.v12i1-2.5410 
Gran, J. (2016). Two corpus-based approaches to rap flow. Empirical Musicology Review, 11(2), 185-186. https://doi.org/10.18061/emr.v11i2.5332

Hirjee, H., \& Brown, D. (2010). Using automated rhyme detection to characterize rhyming style in rap music. Empirical Musicology Review 5(4), 121-145. https://doi.org/10.18061/1811/48548

Horn, E. (2010). Poetic organization and poetic license in the lyrics of Hank Williams, Sr. and Snoop Dogg. $\mathrm{PhD}$ Dissertation, University of Texas at Austin.

Katz, J. (2008). Towards a generative theory of hip-hop. Music, Language, and the Mind. Tufts, Medford MA.

Katz, J. (2015). Hip-hop rhymes reiterate phonological typology. Lingua, 160, 54-73. https://doi.org/10.1016/j.lingua.2015.03.005

Kawahara, S. (2007). Half-rhymes in Japanese rap lyrics and knowledge of similarity. Journal of East Asian Linguistics, 16, 113-144. https://doi.org/10.1007/s10831-007-9009-1

Lerdahl, F., \& Jackendoff, R. (1983). A generative theory of tonal music. Cambridge, Mass.: MIT Press.

Ohriner, M. (2016a). Metric ambiguity and flow in rap music: A corpus-assisted study of Outkast's "Mainstream" (1996). Empirical Musicology Review, 11(2), 153-179. https://doi.org/10.18061/emr.v11i2.4896

Ohriner, M. (2016b). Sampling and features: A commentary on Condit-Schultz (2016). Empirical Musicology Review, 11(2), 148-152. https://doi.org/10.18061/emr.v11i2.5476

Pihel, E. (1996). A furified freestyle: Homer and hip-hop. Oral Tradition, 11(2), 249-269.

Walser, R. (1995). Rhythm, rhyme, and rhetoric in the music of Public Enemy. Ethnomusicology, 39(2), 193217. https://doi.org/10.2307/924425

\section{APPENDIX}

The rhyme data from the 7 songs considered in this commentary are provided as online supplemental materials available at: http://hdl.handle.net/1811/81125. Fields are as follows: artist; song; "Domain" = broad phonetic transcription of rhyme domain; "Pos" = metrical position of first syllable of rhyme domain, in $16^{\text {th }}$ notes within measure; "Dist" = distance between successive rhyme domains in a chain, in $16^{\text {th }}$ notes; "Fin" $=1$ iff rhyme domain is last stress group within a measure; "Sylls" = syllable count of rhyme domain; "Par" = 1 iff two metrical positions involved in a rhyme were also involved in a rhyme during the preceding two measures. 